\begin{tabular}{|c|l|}
\hline Title & $\begin{array}{l}\text { TRITIUM SEPARA TION FACTOR OF SLOW DISCHARGE MECHA NISM OF HY DROGEN ELECTRODE } \\
\text { REACTION }\end{array}$ \\
\hline Author(s) & KODERA, Takuro; SA ITO, Takashi \\
\hline Citation & JOURNAL OF THE RESEARCH INSTITUTE FOR CA TALY SIS HOKKA IDO UNIVERSITY, 7(1), 5-9 \\
\hline Issue Date & 1959-09 \\
\hline Doc URL & http://hdl.handle.net/2115/24688 \\
\hline Type & bulletin (article) \\
\hline File Information & $7(1) \_P 5-9 . p d f$ \\
\hline
\end{tabular}

Instructions for use 


\title{
TRITIUM SEPARATION FACTOR OF SLOW DISCHARGE MECHANISM OF HYDROGEN ELECTRODE REACTION
}

\author{
By \\ Takuro Kodera and Takashi SAITo*) \\ (Received March 10, 1959)
}

\section{$\S 1$. Introduction}

The electrolytic separation factor of hydrogen isotopes is one of important criteria for the mechanism of the hydrogen electrode reaction, inasmuch as it brings about a straightforward information about the critical complex of the rate-determining $\mathbf{s t e}^{122}$.

In their recent paper, to be referred to as I, Kin and one of the present authors ${ }^{3)}$ calculated theoretically the deuterium separation factor, $S_{\mathrm{D}}$, on the basis of the slow discharge mechanism, and showed that the mechanism is quite unsatisfactory for explaining the observed values.

The purpose of the present paper is to extend the calculation to the case of the tritium separation factor, $S_{\mathrm{T}}$, and to confirm further the conclusion of $I$.

\section{$\S 2$. Theoretical Expression for $\boldsymbol{S}_{\mathrm{r}}$}

In $\mathrm{I}, S_{\mathrm{D}}$ was calculated by the expression,

$$
S_{\mathrm{D}}=\left(q^{*(\mathrm{~B})} / q^{*(\mathrm{D})}\right)\left(Q^{\mathrm{HDO}} / 2 Q^{\mathrm{H}_{2} \mathrm{O}}\right) K_{\mathrm{D}},
$$

where $q^{*(\mathrm{H})}$ or $q^{*(\mathrm{D})}$ is the partition function of the critical complex or the Boltzmans factor of the reversible work required to set up the critical complex $*(\mathrm{H})$ or $*(\mathrm{D})$ of the proton or deuteron discharge in a definite, preliminarily evacuated site, $Q^{\mathrm{H}_{2} \mathrm{O}}$ or $Q^{\text {HDO }}$ the partition function of a single $\mathrm{H}_{2} \mathrm{O}$ or $\mathrm{HDO}$ molecule in unit volume of gas, and $K_{\mathrm{D}}$ the equilibrium constant of the exchange reaction,

*) T. K. Department of Chemistry, Faculty of Science, Hokkaido University.

T. S. : Research Institute for Catalysis, Hokkaido University.

**) Eq. (1) etc. in I are quoted here with the numbering (I.1) etc. 


$$
\mathrm{HDO}(g)+\mathrm{H}_{2} \mathrm{O}(l)=\mathrm{H}_{2} \mathrm{O}(g)+\mathrm{HDO}(l) .
$$

Now the similar expression for $S_{\mathrm{T}}$ is obtained from (I.1) and (I. 2) by replacing the quantities relating to the deuteron critical complex $*$ (D) and to the HDO molecule by similar quantities for the triton complex $*(\mathrm{~T})$ and for the HTO molecule, respectively :

$$
S_{\mathrm{T}}=\left(q^{*(\mathrm{H})} / q^{*(\mathrm{~T})}\right)\left(Q^{\mathrm{HTO}} / 2 Q^{\mathrm{H}_{2} \mathrm{O}}\right) K_{\mathrm{T}}
$$

The factor $Q^{\mathrm{HTO}} / 2 Q^{\mathrm{H}_{2} \mathrm{O}}$ in $(1)$ is calculated by the similar expression to (I.4) with the molecular constants') in Table 1, and the equilibrium constant $K_{\mathrm{T}}$ is assumed to be unity, regarding the nearly unity value of $K_{\mathrm{D}}$. Then we have

$$
S_{\mathrm{T}}=154\left(q^{*(\mathrm{H})} / q^{*(T)}\right)
$$

at $20^{\circ} \mathrm{C}$.

TABLE 1. Molecular constants of water ${ }^{4)}$.

\begin{tabular}{ll|l|l}
\hline & $\mathrm{H}_{2} \mathrm{O}$ & HTO \\
\hline $\begin{array}{l}\text { Product of three } \\
\text { moments of inertia }\end{array}$ & $\mathrm{g}^{3} \mathrm{~cm}^{6} \mid$ & $5.87 \times 10^{-120}$ & $29.4 \times 10^{-120}$ \\
\hline
\end{tabular}

\section{$\S 3$. Potential Surface for a Pt Electrode}

The calculation of the factor $\left(q^{*(\mathrm{H})} / q^{*(\mathrm{~T})}\right)$ requires the knowledge of the potential surfaces for the critical complexes. For $\mathrm{Hg}, \mathrm{Ni}$ and $\mathrm{Ag}$ electrodes, we can make use of the surfaces computed in $\mathbf{I}$, on the basis of potential functions proposed by Pansons and Bockris ${ }^{5}$, and Rüetschi and Derahax ${ }^{6)}$. Since, however, the experimental data ${ }^{7)}$ of $S_{\mathrm{T}}$ are available only for a $\mathrm{Pt}$ electrode, we have also computed the potential surface for a $\mathrm{Pt}$ electrode following the procedures of the above authors and of $\boldsymbol{I}$.

As. described in $\mathbf{I}$, the potential surface is determined by the potential energy functions for the initial and final states, $V\left(\mathrm{H}^{+}\right)$and $V(\mathrm{H})$, and the distance $D$ between the centres of the metal atom and the water molecule. Parsons and Bockriss; used the following expres- 
sions for $V\left(\mathrm{H}^{+}\right)$and $V(\mathrm{H})$;

$$
\begin{aligned}
& V\left(\mathrm{H}^{+}\right)=\phi_{d}+\phi_{i}-\phi_{w}+A(r)-\phi_{a}, \\
& V(\mathrm{H})=\phi_{d}+A^{\prime}\left(r^{\prime}\right)+R(r),
\end{aligned}
$$

where $\phi_{a}$ is the dissociation energy of one-half mole of hydrogen $(51.7 \mathrm{Kcal}), \phi_{i}$ the ionization energy of hydrogen $(313 \mathrm{Kcal}), \phi_{w}$ the electronic work function of the electrode metal $\left(5.32 \mathrm{eV}^{8)}\right.$ for $\left.\mathrm{Pt}\right), \phi_{a}$ the adsorption energy of hydrogen ion in the double layer, the value of which is negligible, and the other notations are the same as in I.

Since the constants in the Morse function

$$
A^{\prime}\left(r^{\prime}\right)=A_{0}^{\prime}\left\{2 \exp \left[-a^{\prime}\left(r^{\prime}-r_{e}^{\prime}\right)\right]-\exp \left[-2 a^{\prime}\left(r^{\prime}-r_{e}^{\prime}\right)\right]\right\}
$$

has not yet been spectroscopically determined for the $\mathrm{Pt}-\mathrm{H}$ molecule, we have made the following choice : $A_{0}^{\prime}$ was evaluated to be $-62.9 \mathrm{Kcal}$ by Rǘrsschi and DesahaY ${ }^{6)} ; a^{\prime}$ was determined by the relation between the Monse constants,

$$
a^{\prime}=\sqrt{\ddot{L}} \pi \nu_{e} \sqrt{\mu / A_{0}^{\prime}},
$$

where $\mu$ and $\nu_{e}$ are the reduced mass and the vibrational frequency, respectively, of the molecule; $r_{e}^{\prime}$ and $\nu_{e}$ were estimated at $1.65 \AA$ and $5.37 \times 10^{13} \mathrm{sec}^{-1}$, respactively, by Honiutr and Nakamura ${ }^{9)}$. Thus the equation (I.15) is expressed as

$$
A^{\prime}\left(r^{\prime}\right)=-62.9\left\{2 \exp \left[-1.47\left(r^{\prime}-1.65\right)\right]-\exp \left[-2.94\left(r^{\prime}-1.65\right)\right]\right\},
$$

for the $\mathrm{Pt}-\mathrm{H}$ system.

Finally, the metal atom-water molecule distance $D$ was determined on the assumption,

$$
D=D(\mathrm{Ni})+\frac{1}{2}[d(\mathrm{Pt})-d(\mathrm{Ni})]
$$

where $D(\mathrm{Ni})$ is the similar distance in the case of a $\mathrm{Ni}$ electrode $\left(2.96 \AA\right.$ according to RǗrsschi and DeIAHAY $\left.{ }^{6)}\right)$, and $d(\mathrm{Pt})(2.77 \AA)$ or $d(\mathrm{Ni})$ $(2.48 \AA)$ is the $\mathrm{Pt}-\mathrm{Pt}$ or $\mathrm{Ni}-\mathrm{Ni}$ distance in metallic $\mathrm{Pt}$ or $\mathrm{Ni}$.

From the potential surface thus determined, the force constant $r^{*}$ of the critical complex $*(\mathrm{H})$ on a Pt electrode was computed similarly as 1 . The result is tabulated in Table 2, together with those for $\mathrm{Hg}-$, $\mathrm{Ni}$ - and Ag-electrodes computed in $\mathrm{I}$. 


\section{$\S 4$. Result and Discussion}

Using the values of force constants in Table 2, and the expressions (I.8) and (1.9) as well as the similar ones for tritium, one can easily calculate the vibrational frequencies of the critical complexes, the partition functions, $q^{*(\mathrm{H})}$ and $q^{*(\mathrm{~T})}$, in (2), and hence the values of $S_{\mathrm{r}}$ from (2). The final results are tabulated also in Table 2.

TABLE 2. Separation factor of slow discharge mechanism.

\begin{tabular}{c||c|c|c|c}
\hline \hline Electrode metal & $\mathrm{Pt}$ & $\mathrm{Hg}$ & $\mathrm{Ni}$ & $\mathrm{Ag}$ \\
\hline Force constant & & 21 & & \\
$\kappa^{*}$ Kcal $\AA^{-2} \mathrm{~mol}^{-1}$ & 23 & 24 & 31 & 31 \\
Separation factor & & & & \\
$S_{\mathrm{T}}$ & 37 & 38 & 33 & 33 \\
\hline
\end{tabular}

The Monse function for $\mathrm{Pt}-\mathrm{H}$ was determined in the present paper on some assumptions, as the spectroscopic data have not been known yet. But the value of $S_{\mathrm{T}}$ will be scarecely changed, as actual calculations show, by any reasonable variations of the Monse constants and of $D$, and moreover is expected to become a little larger than the calculated values in Table 2 , for the equilibrium constant $K_{\mathrm{T}}$ must be larger than unity, considering the fact that $K_{\mathrm{D}}$ has the value of 1.07 at $20^{\circ} \mathrm{C}^{10)}$. In fact, the slow discharge mechanism requires that the vibrational frequency $\nu_{\mathrm{H}}$ of $*(\mathrm{H})$ must be $1130 \mathrm{~cm}^{-1}$ in order to give the observed value of $S_{\mathrm{T}}=14$, even if $K_{\mathrm{T}}=1$. This value of $\nu_{\mathrm{H}}$ corresponds to the multiplication of the force constant $\pi^{*}$ by a factor of about 5, which could hardly be covered any reasonable variation of the potential function, too.

Table 3 shows, on the other hand, the theoretical values ${ }^{39911)}$ of $S_{\mathrm{D}}$ as well as $S_{\mathrm{T}}$, which were calculated on the basis of the catalytic and the electrochemical mechanisms, together with the experimental on $\in \mathbf{s}^{2) 7312) 133}$. Here one may observe that the calculated values of the separation factor depend strongly on the mechanisms, but are only slightly affected by different choices of potential functions (compare the values for $\mathrm{Pt}, \mathrm{Ni}$ and $\mathrm{Ag}$, of the same mechanism).

Evidently, the catalytic and the electrochemical mechanisms are successful in explaining the observed values, whereas the results of the 
Tritium Separation Factor of Slow Discharge Mechanism

TABLE 3. Separation factor of various mechanisms.

\begin{tabular}{|c|c|c|c|c|c|c|c|c|}
\hline \multirow{3}{*}{$\begin{array}{c}\text { Separation } \\
\text { factor } \\
\text { Electrode } \\
\text { metals }\end{array}$} & \multirow{2}{*}{\multicolumn{2}{|c|}{ Observed }} & \multicolumn{6}{|c|}{ Calculated } \\
\hline & & & \multicolumn{2}{|c|}{$\begin{array}{c}\text { Slow discharge } \\
\text { mechanism }\end{array}$} & \multicolumn{2}{|c|}{$\begin{array}{l}\text { Catalytic } \\
\text { mechanism }\end{array}$} & \multicolumn{2}{|c|}{$\begin{array}{c}\text { Electrochemical } \\
\text { mechanism }\end{array}$} \\
\hline & $S_{1}$ & $S_{T}$ & $S_{\mathrm{D}}$ & $S_{T}$ & $S \mathrm{D}$ & $S_{T}$ & $S_{\mathrm{D}}$ & ST \\
\hline $\mathrm{Pt}$ & 6.9 & $\begin{array}{l}13.4 \\
14.7\end{array}$ & 13 & 37 & 7.2 & 16.1 & - & - \\
\hline $\mathrm{Ni}$ & 6.7 & - & 12 & 33 & $\begin{array}{l}6.8 \\
7.0\end{array}$ & 15.1 & - & - \\
\hline $\mathrm{Ag}$. & 6.0 & - & 12 & 33 & 5.9 & - & - & - \\
\hline $\mathrm{Hg}$ & $\begin{array}{l}3.1 \\
3.8\end{array}$ & - & 13 & $\begin{array}{l}36 \\
38\end{array}$ & - & - & 3.8 & 5.8 \\
\hline
\end{tabular}

slow discharge mechanism are unsatisfactory. This situation, as pointed out in $I$, is to be attributed to the fact that the critical complex of the slow discharge mechanism is "monatomic", and on the other hand those of the other mechanisms consist of two hydrogen atoms, which are "molecularly" bound: the former is more free to move compared with the latter, giving rise to the too small vibrational frequencies and hence the too large separation factor.

The present authors wish to express their sincere thanks to Professor J. Honiuri for his valuable advice and discussion on the present work.

\section{References}

1) TOPley and Eyring, J. Chem. Phys. 2, 217 (1934).

2) HoRiuti and Oкамото, Sei. Papers Inst. Phys. Chem. Research, Tokio 28, 231 (1936).

3) KeII and KODERA, this Journal 5, 105 (1957).

4) Libby, J. Chem. Phys. 11, 101 (1943).

5) PARSONS and Bockris, Trans. Faraday Soc. 47, 914 (1951).

6) Rüetschi and Delahay, J. Chem. Phys. 23, 195 (1955).

7) Eidinoff, J. Am. Chem. Soc. 69, 2507 (1947).

8) Whitney, Phys. Rev. 50, 1154 (1936).

9) Horiuti and Nakamura, J. Chem. Phys. 18, 395 (1950); this Journal 2, 73 (1951).

10) IKushima and AzaKami, J. Chem. Soc. Japan 59, 40 (1938) (in Japanese).

11) KEII, "Shokubai" No. 3, 30 (1948) (in Japanese).

12) Walton and Wolfenden, Trans. Faraday Soc. 34, 436 (1938).

13) Rome and Hiskey, J. Am. Chem. Soc. 76, 5207 (1954). 